\title{
Innovation Evaluation: Past and Current Models and a Framework for Infrastructure Projects
}

\begin{abstract}
Innovation is a complex and multifaceted phenomenon and very difficult to evaluate but it is at the heart of today's competitive economy. The infrastructure of a nation also plays a crucial role in the economic development of a nation. To gain a sustainable competitive advantage for governments or organizations innovation and infrastructure are two critical factors that need to be effectively employed. This means it is necessary to understand how innovation is created and how it can be applied to infrastructure. The aim of this paper is to develop a framework to evaluate innovation and its benefits in infrastructure projects. For this purpose, a systematic review approach was adopted to review past and current models and frameworks in the literature related to the field of innovation and measurement. As the literature is very fragmented and lacks a consensus on innovation measurement, this paper develops a comprehensive framework with a holistic attitude in mind in order to consider as many as possible elements of the innovation process. The results of this article show a clear understanding of innovation requires evaluating not only inputs and intermediate outputs of the process but also necessitates evaluation of what happens in the process of innovation. The proposed framework is developed in the context of infrastructure projects, and consolidates the measurement of innovation. This area of research is new and relatively unstudied in the context of infrastructure. This study could act as an opening step towards more reliable evaluation of innovation in infrastructure projects.
\end{abstract}

\section{INTRODUCTION}

Innovation as a driver of economic growth has received attention in recent years. The financial crisis, population growth and emerging new technologies such as IT are some of the drivers of innovation. Innovation is viewed by organizations and governments as a prerequisite for competitive advantage and improving productivity in the current turbulent economic situation. For example, innovation is identified as the fifth lever of productivity in the UK [1]. Innovation implementation usually leads to higher standards of living; sustainable profitability; better value to customers and growth in national output. Samson stated that innovation as a differentiator could bring sustainable advantages to organizations. Successful examples are Google, Apple, Samsung, and 3M, which are known internationally as leading innovation-focused firms [2]. The main purpose of innovation measurement is to improve our understanding of growth [3] and improvement. A current major focus in innovation management is on innovation evaluation. In fact innovation measurement more explicitly has become a wish for many organizations. If an organization is seeking to improve its innovation capability, they should have some systematic measures for innovation evaluation and those measures have to be included in the key performance indicators of that organization [2]. In different studies it has been stated that innovation evaluation is a challenging task due to its multifaceted and uncertain nature. There is a variety of measures developed and published such as spending on R\&D practices or statistics of patents and publications in recent years [4]. One common way of evaluation is measuring the inputs to the innovation process such as capital invested for example in R\&D practices. The other way would be evaluating the short-term outcomes of innovation processes like the number of innovative ideas generated or published scientific papers.

Innovation is one of the changes by which organizations are seeking to improve their performance. In fact, by implementing innovations organizations usually gain a competitive advantage over rivals which gives them the chance, for example, to improve the quality of a product or a service. It can also decrease costs in order to gain a higher markup and improve profitability [5]. In order to evaluate innovation outcomes the first important step is to define innovation appropriately. The definitions of innovation have been extended over time from a limited focus on product or R\&D innovation to broader concepts such as organizational innovation, marketing [6] or business structuring. Innovative practices include activities like R\&D, knowledge acquisition, purchase of equipment or machinery, production or delivery preparation, staff training, branding and marketing [5]. 
Referring to economic science there are two ways to increase economic output, first by increasing the number of inputs ( to a certain point only) into a productive process and second by doing things in new ways and get better outcomes with the same amount of inputs [7]. Here is the place innovation comes to play its role.

There are many definitions for innovation because of its complex and multifaceted nature as well as various forms that it can take in different industry sectors [5]. Two of these definitions are mostly referred to in the literature:

The Oslo Manual [8] defines innovation as;

"An innovation is the implementation of a new or significantly improved product (good or service), or a process, new marketing method, or a new organizational method in business practices, workplace organization or external relations".

The minimum requirement is that each of these changes must be new or significantly improved in an organization [8].

Another definition is provided by The Advisory Committee on Measuring Innovation. The Advisory Committee on Measuring Innovation in the 21st Century Economy [9] defines innovation as;

"An innovation is the design, invention, development and/or implementation of new or altered products, services, processes, systems, organizational structures, or business models for the purpose of creating new value for customers and financial returns for the firm".

Based on the second definition, innovation is more than simply something new, it has to add value for both customer and firm. Thus when talking of innovation, care should be exercised about its characteristics in order to get the right meaning. Innovation has five main characteristics including:

- Newness: the practice should be new or significantly improved at least to the organization.

- Being implemented: it is more than just proposing a new idea, it must be implemented or be planned for implementation.

- Making a change: by implementing it something will change, in other words, it has some effects on organizations or projects.

- Creating value: the main purpose of implementing new ideas is adding more value or improving efficiency for organizations or customers.

- Risk: risk and innovation are inseparable concepts. Innovation comes with uncertainties which make the process risky. Thus when defining innovation care should be exercised to take into account uncertainties and risks involved in it.

Infrastructure projects are those major projects which are usually considered at the national level however those are constructed and functioning locally (in a city, state or a region). Infrastructure in this study is defined in accordance with The World Bank's definition (2006) as "the basic framework for delivering energy, transport, water and sanitation, and information and communication technology services to people". It is stated that infrastructure directly impacts people's quality of life, a nation's economic growth and its international competitiveness [10]. Infrastructure Australia has identified seven themes to which infrastructure projects are linked to. Those include National Freight Network, Transforming Our Cities, Adaptable and Secure Water Supplies, National Energy Market, National Broad Band Network, Essential Indigenous Infrastructure and Competitive International Gateway [2].

The present paper proposes a framework for innovation evaluation in infrastructure projects by conducting a review of past and current models, measures and metrics and then synthesizing these findings into a framework. This framework is presented as a comprehensive, holistic approach that considers elements in the process of innovation at the organization/project level. The comprehensiveness of the proposed framework helps to have a full evaluation of innovation elements and prevents partial evaluation of innovation. These consolidated elements will be drawn from previous successful research programs all 
around the world in the field of innovation, evaluation and measurement.

The research method is discussed next followed by the literature review. Past and current evaluation approaches are reviewed in order to identify gaps in the literature. Then the results of an industry survey are presented in order to pre-validate the framework and finally conclusions and the research findings close off this article.

\section{RESEARCH METHOD}

The current investigation involves a review of several successful research projects (not only limited to infrastructure) in order to extract an integrated set of metrics to evaluate innovation in infrastructure projects. For the purpose of this article about 25 references closely related to innovation evaluation and measurement were reviewed. As the infrastructure projects usually deal with nations' performance, a considerable number of reports for innovation evaluation are done at the national level in UK, USA, OECD and Nordic Countries. These reports formed the main part of the literature review. The literature on innovation evaluation is very scattered and it would not be easy to refer to specific journals for the relevant literature. The main national reports reviewed in this article included the reports done in the UK by the National Endowment for Science, Technology and the Arts (NESTA) as well as by the Department of Trade and Industry (DTI), in the USA, the report done by the Department of Commerce, in OECD countries by the Organization for Economic Cooperation and Development, in Australia by the Department of Innovation, Industry, Science and Research (DISR) and in Nordic countries by the Norden Institute called Measuring Public Innovation in the Nordic Countries (MEPIN). Also eight handbooks and books like Handbook of the Economics of Innovation by United Nation University have been reviewed and referred to as well. Besides the above-mentioned references, a number of journal papers from different journals were also included in the literature review (see the references for more information).

The development of the proposed framework was undertaken by consolidating the literature review findings. A conceptual framework was proposed for innovation evaluation in infrastructure projects. This framework necessitates not only the evaluation of inputs to and outcomes of innovation practice but also considers the evaluation of what happens in the process of innovation.

In order to validate the proposed framework, twenty interviews with industry professionals were conducted. The interview was structured in a two pages document and was prepared to the interviewees via email few days prior to the interview. The interviewees were chosen from the companies dealing with infrastructure and major construction projects via the authors' industry links. The interviews were undertaken in person as well as on the phone over a period of six months from January to June 2015. Not all of the information gathered via interviews was used in this paper. Part of the information is reported in other articles related to the whole study. Thus the information related to the validity of the framework is included in the current article.

The proposed conceptual framework was introduced to the industry people and their feedback was sought. Also two questions were asked, first their opinions about the appropriateness of the framework and if any element was missing and secondly the level of importance of three categories of factors in the framework (input, process and outcome) in terms of evaluation. Their feedback and answers are summarized in section 6 after the gap and discussion section.

Organizations usually adopt two approaches to gather data for innovation evaluation. One approach is the "subject approach" by which the project or organization's performance as a whole in terms of innovation is explored thus outcomes of projects are evaluated considering the innovation involved. The other approach is the "object approach" where a specific innovation practice or activity is considered for collecting data for evaluation purposes [5]. In the current study, the proposed framework would concentrate on the first approach that is more amenable and practical can be used in other industry fields too.

To provide a comprehensive set of evaluation criteria for innovation evaluation, related papers have been collected from various fields of research such as construction, IT, public sector organizations and SMEs as well as those ones which are frequently referred to in the literature such as OECD publications. The selected papers were categorized based on what they have considered as evaluation elements in the process of innovation, for example evaluating the inputs, outputs or conditions and requirement for innovation. Subjectivity and objectivity of evaluation were other considerations in this review like evaluating capital investment or 
intangible assets in the process of innovation. Then all the elements for evaluation were categorized into three categories of inputs (for assessing the capacity of organization to innovate), process elements (in order to evaluate the capability of organizations to implement and manage innovation process) and finally outcomes (to evaluate performance of an organization as a result of undertaking innovation practices). For assessing these three groups of factors, both tangible and intangible assets were taken into account. A detailed overview of the measures mentioned above is discussed later in the paper.

\section{LITERATURE REVIEW}

In this section, the related literature in terms of evaluation methods in general and innovation evaluation methods are reviewed respectively. Measurement and innovation are seen as the basis of success for businesses these days. Managing innovation would be difficult without measuring it, and this evaluation is critical for both practitioners and academics. In the following section, the literature is reviewed in order to bring together disparate indicators and measures to develop a holistic model for innovation evaluation. First evaluation approaches will be reviewed followed by different approaches for innovation evaluation. Then the scales of evaluation (from higher level like national level to lower like project level) are examined and finally the evaluation of tangibles, intangibles, R\&D, and technology will be discussed.

\subsection{Evaluation methods in general}

Evaluation and measurement have been used interchangeably for innovation in the literature, but these two concepts do not mean the same thing. Based on Spritzer's definitions of measurement and evaluation in his book, these two terminologies are always confusing. When evaluating something we place a value on that and its outcome is a judgment. In fact, evaluation is all about value judgments while measurement needs to be nonjudgmental. In other words, measurement is the process of collecting and analyzing the information and data about something in order to understand it better. Thus measurement is naturally neutral. Evaluation should be always based on solid measurement to be reliable and effective. Also evaluation might be used when something cannot be measured. Evaluation without measures is usually judgmental and subjective while measurement is based on figures and numbers which are called metrics. These two concepts are a bit different and should be distinguished. Measurements are inputs to the evaluation process, and reliable evaluation is totally dependent on solid measurement [11]. The main purpose of measurement is learning from it for different purposes. Management is based on measurement and other organizational activities are all dependent on measurements such as total quality management (TQM) or Six Sigma concepts. What makes measurement important in the context of innovation is learning from it for different purposes like evaluation.

Organizations seek changes for various reasons and one of those reasons could be performance improvement. Thus from an organizational perspective it will become important how to evaluate the impacts of these changes on performance. At the firm/project level innovation is seen as a change and its measurement is central to provide information to understand and evaluate performance of the firm/project.

There are several generic approaches for evaluation including qualitative, quantitative and a combination of these two. Brief explanations of these approaches are provided in the below and tabulated in Table 1.

Quantitative approaches: used when benefits can be assessed quantitatively and some metrics such as time, cost and revenue can be used as evaluation criteria.

Qualitative approaches: when there are valuable benefits that are difficult to measure; the best way to assess them is surveys of clients, customers and users. For example experts' and practitioners' viewpoints may be accepted as a basis for evaluation. A customer experience survey is an application of this kind that is qualitative in nature.

A Combination of quantitative and qualitative approaches: sometimes there are several aspects of projects that 
can be assessed quantitatively while some of them can only be evaluated qualitatively. This kind of assessment could result in more reliable outcomes if there is a focus on the whole of life cost benefits analysis. This method can be used for performance measurement. Time, capital cost, operational cost, productivity, efficiency, and energy consumption are usually assessed in this method. Table 1 summarizes the characteristics of these evaluation approaches.

Table1: Different Methods for Benefit Evaluation

\begin{tabular}{|c|c|c|}
\hline Method & Example of use & Example of Indicators \\
\hline $\begin{array}{l}\text { Quantitative } \\
\text { Method }\end{array}$ & $\begin{array}{l}\text { Project } \\
\text { Success }\end{array}$ & Time and cost, key performance indicators (KPIs) \\
\hline $\begin{array}{l}\text { Qualitative } \\
\text { Method }\end{array}$ & $\begin{array}{l}\text { Customer } \\
\text { Experience }\end{array}$ & Opinion surveys of users and experts \\
\hline $\begin{array}{l}\text { Quantitative/ } \\
\text { Qualitative } \\
\text { Method }\end{array}$ & $\begin{array}{l}\text { Performance } \\
\text { Evaluation }\end{array}$ & $\begin{array}{l}\text { Time, capital costs, operational costs, productivity, efficiency, } \\
\text { effectiveness, energy usage, economic ratios (ROI, BCR, NPV), } \\
\text { benchmarking such as PSC in PPP projects, revenue }\end{array}$ \\
\hline
\end{tabular}

In terms of economic and financial evaluation, there are several methods that can be used in different situations based on the intended accuracy, available time, information and types of projects. Some of these methods include cost-benefit analysis, financial analysis, cost-effectiveness analysis and socio-impact analysis [12]. For financial analysis different measures may be used such as Net Present Value (NPV), Net Present Cost (NPC), Internal Rate of Return (IRR), Benefit Cost Ratio (BCR) and so forth. Explaining these methods is out of the scope of this article. As each project has a proper economic evaluation, the proposed framework in this article does not add any extra economic calculation. In fact, it will do a subjective assessment based on those calculations in each project.

\subsection{Different approaches to innovation evaluation}

From a business perspective the main purpose of implementing innovative practices is to improve performance of firms/projects; like increasing the market share, improving the quality, enhancing the client base, increasing the profit or even surviving in the market. Thus there should be a realistic evaluation approach in place in order to track the outcomes of innovation practices. Innovation evaluation has gone through a period of history starting from 1950s till now. During this period, evaluation measures have been emerging and improving. At the beginning the main focus was on R\&D activities and technology as inputs (investment) to the process of innovation. Gradually the focus has shifted to assessing the intermediate outputs such as patents counts or publication records. Then by having some public data available the focus of metrics has changed towards benchmarking of nations' capacity to innovate or the level of competitiveness. Recently the emerging indicators are trying to consider the broader outcomes of innovation by examining innovation as a process in nature [3]. These broader outcomes include knowledge, social and environmental impacts. Another point here is that innovation should not be evaluated only based on short-term returns and outcomes because there are always long-term payoffs associated with innovation, however, those might be sometimes uncertain[13].

Milbergs and Vonortas categorized innovation metrics into four generations of indicators as follow:

- Input indicators (1950s-60s): focusing on inputs and reflecting the linear concepts of innovation. They include examples of R\&D investment, education and training expenditures, research personnel and the like.

- Output indicators (1970s-80s): these are complements to input indicators by focusing on intermediate outcomes such as number of patents and publications, new products and processes and so forth.

- Innovation indicators (1990s): these are richer indicators based on a survey of public and available data. Their focus was on benchmarking and nations' ranking in terms for example capacity to innovate or international competitiveness.

- Process indicators (+2000): these are new and emerging indicators with the main focus on processes. They 
include knowledge indicators that consider networks, economic demands, public policy environment, infrastructure conditions, social attitude and cultural factors. The fourth generation are very important but, unfortunately, remain ad hoc because they have many dimensions and are not easy to measure [3].

What makes innovation difficult to measure is its uncertain and multifaceted nature. The reason for this uncertainty is because innovation outcomes are to some extent unknown, and the process itself involves risks [14]. Another fact that makes the innovation evaluation difficult is the social or public benefits of innovation due to the spill-over process that are not easy to measure. The other hard to measure aspect of innovation is knowledge that might not be fully captured by innovator firms as an outcome [5].

The measures of investing in R\&D or counts of patents and publications were called indirect indicators of innovation by Tether in an assessment of the Community Innovation Survey (CIS) in the Center for Research on Innovation and Competition at the University of Manchester. He believed that both the first version of the Oslo Manual and CIS were important steps in innovation evaluation, but they were designed solely for a manufacturing concept and did not include service or construction innovation. Updated versions have embraced service innovation as well [15]. This shows that the measures of innovation have been improving over time.

\subsection{Scale (Level) of evaluation for innovation}

Innovation occurs at different levels such as national, industry sector, organization and project level. The information and data related to implemented innovations are documented and stored at those levels. Each level requires its appropriate way of evaluation. In other words innovation evaluation needs to be undertaken at these levels. National and sectoral evaluation usually relates to economic growth and GDP as well as the extent of global competitiveness of nations. This can be called macro-level evaluation. What happens at firm and project levels is called micro-level evaluation which is the level of evaluation in this study but it is useful to review studies at national and industry sector levels for the purpose of this study.

\subsubsection{National level}

Innovation

Several researches were done at national levels in different countries. The United States, UK, and some other European countries have been investing in the research related to innovation, its evaluation and effects on national growth. Many researches done at the national levels were by OECD, which has being done for few years. What they have done is more like innovation surveys to benchmark and compare OECD countries. [8]. They have tried to improve this set of guidelines over time and their main focus at the beginning was on R\&D spending by businesses or statistics related to patents and publications as well as products related measures such as number of new products. The subjects they have been covering by innovation subject included: product and process innovation; investment in innovation; soft and wider innovations such as management-related concepts [16].

Another report providing innovation indicators is a series of ten-year reports from 2004 to 2014 by HM Treasury in the UK known as a Framework for Science and Innovation Investment [17]. In the HM Treasury survey different sectors such as manufacturing, engineering, construction, retail and services were studied in terms of innovation. For example; in the construction sector the highest share of investment in innovation was related to training while the lowest ones were design functions [16]. The expenditures in this survey are categorized into acquiring knowledge, R\&D, Marketing, Design, training and acquisition of machinery, equipment and software. In the HM Treasury survey the skill and capability of employees as one of the most important factors for innovation was evaluated by the percentage of employees attaining different levels of education. As it can be seen from the word Investment in the name of the framework by HM Treasury, these evaluations are mainly 
focused on inputs indicators.

The National Endowment for Science and Technology and the Arts (NESTA) is another organization that tries to promote innovation in the UK. This organization is famous for its national evaluation of innovation known as NESTA's Innovation Index that reflects how innovation occurs and also quantifies the importance of innovation to provide better guidance for policy making. One of the results of this study showed the importance of innovation in the UK's economy by stating that two-thirds of UK private productivity growth in the period 20002007 was due to innovation investment[6]. This study had four objectives including; measuring the amount of investment in innovation in the UK; to capture hidden innovation at the firm level by developing a tool; assessing the climate for innovation in the UK; and finally defining a measure to assess public sector innovation. The term "hidden innovation" referred to organizational innovation, investing in required skills, design and branding. Hidden innovation here refers to softer aspects other than traditional research and development which include training \& skills development, organizational improvement, market research and advertising.

In the study by NESTA, investments are categorized into different groups including R\&D, Design, Organizational Improvement, Training \& Skill Development, Software Development, Market Research \& Advertising and others such as copyright development and mineral exploration. Innovation in the service industry sector can occur by investing in organizational improvement and training. Internet banking is an example of this kind that includes investment in IT and training to make use of the service [6].

The results of the NESTA study showed that R\&D with $11 \%$ of total investment was the fifth largest investment in innovation among seven categories while organizational innovation was the second largest after investment in training followed by design investment as the third one [6]. These results show the importance of investing in intangible asset compared to tangibles.

Like other countries, the US has invested considerably in innovation measurement. The study done by The Advisory Committee on Measuring Innovation in the 21st Century Economy in 2008 is one example in the United States. This study proposed and suggested many recommendations for government, business communities, researchers and practitioners in terms of innovation promotion and measurement [9].

However the above-reviewed articles are showing some sort of evaluation of innovation at national level but still there is a need to evaluate innovation at the other level like industry and firm or project level. The next section brings few examples of innovation evaluation at industry sector level.

\subsubsection{Industry sector level}

The industry level includes different sectors of industry such as mining, agriculture, the public sector, construction, IT or infrastructure. One of the areas of interest for research in recent years has been the assessment of innovation in the public sector. Innovating is recognized as a powerful strategy to develop solutions to many environmental, social and economic challenges by the public sector [18]. As most infrastructure projects relate to public service in some way, having discussed innovation in the public sector and its measurement would be helpful for the aim of this study. Two recent examples of this kind are: The APSII project in 2011 by the Department of Innovation, Industry, Science and Research as the first step in measuring innovation in Australia and the MEPIN project in 2011 in Norway which will be discussed later on in the paper.

When measuring innovation in the public sector, the fundamental differences between public and private sectors should be considered. Some of these differences could be a budget constraint, organizational objectives and conditions such as decision-making or incentive strategies. For example while in the private sector profit plays a critical role, in the public sector the main concern is providing better service to the society (like enhancing people's well-being) [19]. 
In Australia, the Australian Public Sector Innovation Indicators (APSII) Project commenced in late 2010 by the Department of Innovation, Industry, Science, and Research. In this project also it has been stated that evaluating public sector innovation is a hard task because of the broad and long-term nature of outcomes of innovation in the public sector. Thus, they suggested using survey questions to evaluate the effects of innovation such as improvement in quality and efficiency, costumers and employees' satisfaction and so forth [18]. In fact, this point restates the tolerance of subjective assessment in innovation evaluation as well as using composite indicators in this regard.

The APSII framework suggested four categories for consideration including Inputs, Processes, Outputs, Outcomes and Environmental Conditions for public innovation. The criteria put forward by the authors in terms of practicality of indicators were measurable, informative, developmental, cost-effective, engaging, forwardlooking and comparable adjectives. Six areas were identified for analytical evaluation including innovation activities, impacts of innovation, staff innovation potential, innovation management practices, innovation culture and strategy, innovation barriers and drivers. This framework is one of the comprehensive models for innovation measurement that has been developed so far however still it remains at an abstract level and needs to be further developed to be applied as a tool by practitioners. Also, it lacks consideration of risks associated with innovation that may affect the outcomes of innovative practices.

\subsubsection{Organization/project level}

The evaluation at firm and project levels is usually mixed up in the literature. One of the examples of innovation evaluation at the organization level is the research by Anderson et al. (2000). They developed a framework for measuring the benefits of IT innovation in the construction industry. Three main benefits identified were business efficiency, effectiveness, and performance. The purpose of this framework was to provide a common business language for construction practitioners to make wise decisions by investing in IT. The authors stated that among available evaluation approaches the best way for evaluation would be quantification and comparison of intangible benefits while direct economic costs and benefits of investment are available. Their framework measures efficiency in monetary term, effectiveness in the non-monetary term and quantifies performance qualitatively by judgmental approaches. The business processes identified in this framework included business planning; marketing; information management; procurement; finance; client management; design; construction; occupation and maintenance; and human resources. [19]. However this evaluation framework is included in the organization level but it can be used at the project level as well.

Although some articles were found at the project level, the literature is still lacking specific research to evaluate innovation at this level. In the below two examples are briefly discussed however those might not be completely related to innovation evaluation.

One of these studies is the work done by Murphy and his colleagues. Murphy et al. in 2011 developed a conceptual model that mapped different phases of project procurement against innovation process. Their main purpose is to develop an approach to realize innovation constraints of building projects through stakeholder management competencies and failure mode and effect analysis (FMEA). In this model they believed a stakeholder-centered approach is required to get successful innovation by having the right stakeholder competencies in place at the right stage of the procurement process. In fact, the main focus of this model is on stakeholders instead of the innovation process itself [20]. The primary findings of their model were the development of a risk management method to be used by the project stakeholders in order to mitigate the risks due to uncontrolled constraints in the innovation process.

In a research paper, Pellicer et al. introduced a simple innovation model in order to identify the drivers, success factors, benefits, and barriers to innovation in a medium size construction companies. In their model drivers are emerging novel ideas, the results are the innovation projects and related benefits, the environment include both the boundary of the organization as well as the construction industry umbrella as a whole [21]. 
As was mentioned previously, the literature is lacking a particular approach of innovation evaluation at the project level. The purpose of the current research is to bridge this gap in the literature and is intended to continue in future.

\subsection{Evaluation of tangibles, intangibles, R\&D, and technology}

Discussing the evaluation of tangibles and intangibles or R\&D practices is vital in order to have a better understanding of innovation evaluation. Intangible assets are the outcomes of investments in knowledge capital while tangibles are defined as physical and labor capital [6]. In the modern economy, intangible assets are as important as tangible assets. On the other hand almost more than half of the economic growth is attributed to intangible inputs compared to conventional inputs like labor and capital. Intangible assets are key inputs to the innovation process as well. Understanding and measuring innovation necessitates the consideration of intangible assets[22]. To evaluate intangible inputs, it would be possible to use investment in these types of assets but the most difficult part will be evaluation of the outputs of these investments and how they contribute to the performance of the organizations as a whole. For example knowledge creation and advances as a result of investing in R\&D practices are hard to measure. Branding, marketing, and advertising, as well as training and education, are other examples of investment that all lead to economic competitiveness and yet are hard to measure because they are intangible assets. It is worth mentioning that some of these investments (such as branding) might not be applicable to infrastructure projects. Knowledge in all different forms has a vital role in today's economy. Investment in the creation of knowledge might lead to economic growth. For example firms and individuals with more knowledge perform better and more productively [10]. These investments include spending on human capital (training and education), research and development (scientific, product, market) and management and organizational development. The outcomes of these investments usually fall under the category of intangible assets[23]. Corrado et al. believed that most of the investment in intangibles could be seen as investing in innovation. For example, a higher rate of GDP growth is directly related to higher investing in intangibles. In other words, the intangible investment could be used as an indicator in innovation evaluation. More importantly the long-lasting benefits from investing in intangibles are of paramount value that can lead to growth through diffusion and spill-over of knowledge. Empirical measurement of these types of benefits is one of the main concerns of practitioners and scholars.

The problem with cost indices for intangibles outcomes is that these measures ignore the productivity gains in producing these assets [22]. Thus, one possible evaluation approach could be taking advantage of subjective assessment using judgment surveys. This can be also combined with cost indices to give more reliable evaluation.

However, the definitions of innovation provided in the introduction show that innovation is more than simply investing in R\&D practices but many researchers only studied the relationship between R\&D activities and innovation. The definitions make it clear that innovation involves applying knowledge, commercialization, tangible and intangible assets, skills and technology[9]. Measuring economic returns to R\&D practices is related to the fact that $R \& D$ creates a knowledge base in organizations which in turn leads to future long-term benefits [24].

There are two problems with using investing in R\&D as an evaluation criterion. First, it is only an input to the process of innovation, and secondly it does not embrace all the efforts of firms in the innovation process such as training or learning [5]. To put it in a nutshell, investing in intangibles is more important than investing only in tangible assets. This is confirmed by the results of the NESTA study which showed among seven categories, organizational innovation was second followed by investment in training and design while R\&D with 11\% of total investment was the fifth largest investment. 
One of the outcomes of investing in R\&D practice could be patents or publications that can be used as evaluation indicators. Using statistics related to patents has drawbacks as well because many innovations may not lead to a patent and also a patent might not result in an innovation, economic growth or improvement [5]. Monetary figures or other statistics have become easy and straightforward measures for innovation evaluation but these criteria could not be used solely thus other factors have to be considered as well.

\subsection{Main findings from the literature review}

Researchers have raised concerns in relation to innovation evaluation that are useful for the purpose of the current study and would be applicable in infrastructure projects as well. The most important concerns were provided in OECD report in 2010 and few more by Schramm et al. in 2008. OECD report re-emphasized that in order to improve measurement of innovation there needs to be a link between the outcomes and microeconomic performance. Also they restated the importance of intangible evaluation as well as considering and measuring the social impacts of innovation. OECD report pointed out for better measurement of innovation impacts there needs to have higher quality infrastructures and data gathering.

Schramm et al. also put forward few concerns and comments. The most important comment by them was tolerating qualitative and subjective evaluation methods for innovation. The strongly believed that innovation evaluation could not be static and it needs to be iterative and collaborative. They also pointed out that measurement approaches should allow evaluation of innovation at different levels including firm, industry, region, country as well as international level. In their comments there was a mention of outcomes assessment as the main focus of evaluation process.

The above-summarized points are all important in the process of innovation evaluation. All these comments confirm the gap which is going to be bridged by the current study is a real gap in the literature as well as the industry. All those points are considered when proposing the evaluation framework for infrastructure projects.

\section{PAST AND CURRENT EVALUATION APPROACHES}

Based on the literature, the metrics for innovation are of two kinds. "Soft" metrics which are usually evaluated qualitatively and basically relate to intangible such as knowledge or vision. "Hard" metrics which can be measured quantitatively and associate with tangibles and statistics such as monetary investment or number of new products [14].

In addition to research done on different aspects of innovation, as well as its various metrics, there are also several good studies that are focused more on developing evaluation frameworks for innovation in different industry fields. However, these studies are disaggregated and separate but still could be used as the building blocks for the current paper. For the purpose of this research, the most important frameworks or tools for innovation evaluation are presented and discussed. The major research projects done previously are summarized in Table 3.

Table 3: Some of the innovation measurement research projects

\begin{tabular}{|l|l|l|}
\hline Title of research project & $\begin{array}{l}\text { Organization } \\
\text { /Author }\end{array}$ & Comments \\
\hline \multicolumn{2}{|c|}{ National Projects- Current (After 2009) } \\
\hline $\begin{array}{l}\text { European Public Sector } \\
\text { Innovation }\end{array}$ & $\begin{array}{l}\text { Hugo Hollanders } \\
\text { et al. }\end{array}$ & $\begin{array}{l}\text { The EPSIS project uses a measurement framework similar to that used } \\
\text { for the Innovation Union Scoreboard (IUS). It is aiming at collecting data } \\
\text { on seven innovation dimensions ranging from human resources to } \\
\text { drivers and barriers to innovation. }\end{array}$ \\
\hline $\begin{array}{l}\text { The Global Innovation } \\
\text { Index (GII), 2008-2013 }\end{array}$ & $\begin{array}{l}\text { Different authors } \\
\text { during six years }\end{array}$ & $\begin{array}{l}\text { The GII is a tool developed in the mid-2000s by the Ministry of } \\
\text { Government Administration and Home Affairs, Republic of Korea (South } \\
\text { Korea), to gauge the level of innovation of organizations in the South } \\
\text { Korean public sector. The GII looks at various areas to determine how } \\
\text { well an organization innovates amidst changing environments. }\end{array}$ \\
\hline
\end{tabular}




\begin{tabular}{|c|c|c|}
\hline & & $\begin{array}{l}\text { Over the course of the last six years, the GII has established itself as a } \\
\text { leading reference on innovation for researchers and public and private } \\
\text { decision makers. It has evolved into a valuable benchmarking tool to } \\
\text { facilitate public-private dialog. }\end{array}$ \\
\hline $\begin{array}{l}\text { Community Survey (CIS)- } \\
2008-2012\end{array}$ & OECD & $\begin{array}{l}\text { It is a survey of innovation activities of enterprises in Ireland and other } \\
\text { EU Member States. The survey collected information about product and } \\
\text { process innovation, organizational and marketing innovation and other } \\
\text { key variables. }\end{array}$ \\
\hline $\begin{array}{l}\text { Measuring Public } \\
\text { Innovation in the Nordic } \\
\text { Countries (MEPIN), } 2011\end{array}$ & Carter Bloch & $\begin{array}{l}\text { It is a project aiming at developing a measurement framework for } \\
\text { collecting internationally comparable data on innovation in the public } \\
\text { sector in the Nordic countries. }\end{array}$ \\
\hline $\begin{array}{l}\text { Working towards a } \\
\text { measurement } \\
\text { framework for public } \\
\text { sector innovation in } \\
\text { Australia (APSII), } 2011 \\
\end{array}$ & $\begin{array}{l}\text { Department of } \\
\text { Innovation, } \\
\text { Industry, Science, } \\
\text { and Research }\end{array}$ & $\begin{array}{l}\text { It is aiming to equip public sector organizations with data and indicators } \\
\text { to obtain a better understanding of their innovation performance and } \\
\text { capability, and to drive decisions to achieve better organizational } \\
\text { outcomes. }\end{array}$ \\
\hline $\begin{array}{l}\text { The Innovation Index: } \\
\text { Measuring the UK's } \\
\text { investment in innovation } \\
\text { and its effects, } 2009\end{array}$ & NESTA & $\begin{array}{l}\text { NESTA measures a broad range of innovative activity, from the R\&D that } \\
\text { lies behind innovative technologies to the service design and } \\
\text { organizational innovations that power the UK's service industries. It links } \\
\text { investment in innovation to productivity improvement and economic } \\
\text { growth. }\end{array}$ \\
\hline \multicolumn{3}{|c|}{ National Projects- Past (Before 2008) } \\
\hline $\begin{array}{l}\text { Innovation } \\
\text { Measurement: Tracking } \\
\text { the state of innovation } \\
\text { in the American } \\
\text { economy, } 2008\end{array}$ & $\begin{array}{l}\text { The Advisory } \\
\text { Committee on } \\
\text { Measuring } \\
\text { Innovation } \\
\text { in the 21st Century }\end{array}$ & $\begin{array}{l}\text { This research is not on innovation measurement, but it is mainly focused } \\
\text { on developing recommendations to improve innovation measurement. } \\
\text { Most of the recommendations are on innovation drivers, impediments, } \\
\text { and enablers. }\end{array}$ \\
\hline \multicolumn{3}{|c|}{ Individual Projects- Current (After 2009) } \\
\hline $\begin{array}{l}\text { Frameworks for } \\
\text { Measuring Innovation: } \\
\text { Initial Approaches, } 2009\end{array}$ & Athena Alliance & $\begin{array}{l}\text { This report extends the previous work and presents two alternative } \\
\text { frameworks for measuring innovation. The first framework focuses on } \\
\text { measuring innovation activities at the firm/organization level. The } \\
\text { second takes a broader macro-level look at the fundamental investments } \\
\text { that allow firms and other organizations to carry out innovation } \\
\text { activities. }\end{array}$ \\
\hline \multicolumn{3}{|c|}{ Individual Projects- Past (Before 2008) } \\
\hline $\begin{array}{l}\text { Innovation Metrics: The } \\
\text { Innovation Process and } \\
\text { How to Measure It, } 2008\end{array}$ & $\begin{array}{l}\text { Langdon Morris } \\
\text { (Innovation Labs } \\
\text { LLC) }\end{array}$ & $\begin{array}{l}\text { This research introduces possible metrics to be used at different stages } \\
\text { of the innovation process and has a subjective approach to evaluating } \\
\text { innovation mainly by proposing different questions. }\end{array}$ \\
\hline $\begin{array}{l}\text { Innovation management } \\
\text { measurement: A review, } \\
2006\end{array}$ & $\begin{array}{l}\text { Richard Adams, } \\
\text { John } \\
\text { Bessant } \\
\text { and } \\
\text { Robert Phelps }\end{array}$ & $\begin{array}{l}\text { This research attempts to develop a holistic framework covering the } \\
\text { range of activities required to turn ideas into useful and marketable } \\
\text { products by reviewing the literature pertaining to the measurement of } \\
\text { innovation management at the level of the firm. This framework consists } \\
\text { of seven categories: inputs management, knowledge management, } \\
\text { innovation strategy, organizational culture and structure, portfolio } \\
\text { management, project management, and commercialization. }\end{array}$ \\
\hline $\begin{array}{l}\text { Innovation in the UK: } \\
\text { Indicators and Insights, } \\
2006\end{array}$ & DTI Economics & $\begin{array}{l}\text { This is the fourth series of innovation surveys in the UK. The survey } \\
\text { sought information on the nature of the business activities involved in } \\
\text { innovation as well as the effects of product and process innovation on } \\
\text { market position, internal processes and costs. }\end{array}$ \\
\hline $\begin{array}{l}\text { Innovation Metrics: } \\
\text { Measurement to Insight, } \\
2004\end{array}$ & $\begin{array}{l}\text { Egils Milbergs } \\
\text { and } \\
\text { Nicholas Vonortas }\end{array}$ & $\begin{array}{l}\text { This project is done at IBM Corporation with the purpose of highlighting } \\
\text { the importance of high quality, relevant and more timely innovation } \\
\text { metrics in enhancing public understanding, helping policymakers to } \\
\text { benchmark the nation's innovation performance, and thereby improving } \\
\text { policymaking and business strategies. }\end{array}$ \\
\hline
\end{tabular}

In a review by Milbergs and Vonortas in 2004 at the Centre for Accelerating Innovation at IBM, it is restated that 
there is a need for improved metrics in order to reflect the characteristics of knowledge-based economy to guide government in innovation policy making and to cope with uncertainty involved in innovation process. These types of metrics are called fourth-generation or emerging metrics for innovation in the literature and are including but not limited to knowledge indicators, networks, demand for innovation, intangibles and condition for innovation. Unfortunately, this generation of metrics does not have analytical value due to their ad hoc nature. They concluded that innovation metrics had to be expanded to open up the possibility of developing new analytical tools for innovation assessment [3].

A comprehensive review work on innovation evaluation was done by Adam et al. in 2006 titled as "Innovation Management Measurement". They called the output of their work an analytical framework for innovation management process at the firm level. This framework comprises seven categories as inputs management, knowledge management, innovation strategy, organizational culture and structure, portfolio management, project management and commercialization. The purpose of the framework is mapping the management of innovation measurement by defining and illustrating each category with appropriate and empirical sets of measures [1]. However this is one of the comprehensive frameworks in the literature but the outcomes of the innovation process is not included in the framework thus the benefits of innovative practices cannot be fully assessed by applying this model. The other thing is that although there is a risk title included in the framework still there is no practical approach to consider impacts of risks on innovation outcomes. In fact, this framework focuses more on inputs and the process of innovation.

Morris at Innovation Labs LLC in 2008 has done a research study that was more focused on a qualitative evaluation approach to the innovation process, and more likely it is developed for product innovation. In this work, he identified nine stages for the innovation process and proposed a number of questions for each stage in order to assess the innovation process. Strategic Thinking, Portfolio Management \& Metrics, Research, Ideation, Insight, Targeting, Innovation Development, Market Development and Selling are different stages of the innovation process in this framework. Other than staged-linked metrics the author introduced transversal metrics that are more related to human resources and learning again with qualitative evaluation nature [14]. One of the good aspects of this study is that the whole process of innovation is considered for evaluation but the framework is used more as a guideline rather than a decision-making tool. It is very subjective in nature, however, there are some questions for quantitative measurement, but there are no evaluation method specified for them.

In 2009 Rose et al. undertook research to develop a framework to measure innovation. In their study, they tried to find out how tangible and intangible assets relate to the innovation process. They considered tangible assets such as production facilities, technology and intangibles like R\&D, intellectual property (IP) and organizational structure as inputs to the process of innovation. They called some activities like R\&D, design, prototyping, marketing and trading as innovative activities. On the other side what they considered as the output of the innovation process included final outcomes such as new and improved products or processes and innovative capital such as IP, competencies, and human capital. They discussed two frameworks in their work; the first one for measuring intangible assets created by innovation process and the second one for measuring innovation investments. They illustrated assets in three categories as human capital (training and experience), intellectual capital (R\&D, databases, patent, music, licenses, and trademarks) and organizational capital (ICT infrastructure, networks and alliances, business models and design). This frameworks can act as illustrative models rather than definitive measurement tools [25] and are only used as guidelines.

Also Rose et al. defined ten attributes for innovation and believed that these attributes make the evaluation of innovation difficult [25]. Those are summarized into the five following points:

- Innovation involves: a combination of inputs to create outputs; activities with the purpose of creating economic value; risk; R\&D; and commercialization.

- Inputs to innovation are both tangible and intangible. These inputs are in fact assets.

- Knowledge is a key input as well as a key output of innovation.

- The innovation process is complex and is not a linear process also not limited to the firm's boundaries.

- The outcomes of innovation process could be unpredictable.

Public innovation could be related to infrastructure projects as it has to do with people. Two of the most recent studies that were mentioned previously are briefly discussed here. One of these studies was done in 2011 by 
Department of Innovation Industry, Science, and Research as the first step in measuring public innovation in Australia. The APSII's Framework consists of five themes; inputs to innovation, innovation processes, outputs of innovation, outcomes of innovation, and environmental conditions affecting innovation. The framework includes several areas of assessment including: Innovation Activities, Impacts of Innovation, Staff Innovation Potential, Innovation Management Practices, Innovation Culture and Leadership, Agency Innovation Strategy, Innovation barriers and drivers [18]. Again in this framework innovation risks and their impacts on the outcomes are ignored. The other thing is that this framework can be applied as a guideline only, and there is no specific practical method introduced for evaluation.

Another research project in the field of public innovation is MEPIN which was intended to develop a framework to gather international data to compare Nordic countries performance. It was more like a survey questionnaire with some quantitative and qualitative measures. This project is a part of larger study called Copenhagen Innovation Manual. They claimed that there were some measures for evaluating input to innovation and outputs of innovation [26]. There are several main issues with this framework first the level of evaluation that is at national level with the purpose of international comparison. Secondly, the reliability of international data and information that hangs some question marks on the assessment. Thirdly, it only looks at past data or information without any evaluation of future outcomes. Fourthly, there is no risk discussion involved in the process of evaluation.

However, although the above-mentioned types of measurements are widely accepted and relate to a linear model of innovation, there remains a pressing need to evaluate longer term outcomes of innovative practices such as social and economic outcomes as well as providing a holistic approach to assess the innovation process as a whole including inputs, the process itself and the outcomes (both short and longer term). In the past studies, little emphasis has been placed on the process of innovation and related measures. Having reliable and robust innovation metrics will help in different ways such as enhancing public understanding, benchmarking nation's performance, assisting business decision-making [3]. Thus the need for a comprehensive approach to better understand innovation process and outcomes seems to be urgent.

It is fairly evident that in order to have a solid evaluation of innovation; it is necessary to look at all elements of innovation including inputs and outcomes as well as the process of innovation. Assessing one element in the absence of others might give a partial assessment that would not be reliable for making wise decisions. Thus, the need for a comprehensive and holistic approach for evaluation becomes quite evident. In the next section, a fundamental and basic framework for such an approach will be proposed and discussed.

\section{FRAMEWORK DEVELOPMENT}

Innovation is multifaceted and complex activity with non-linear dynamic characteristics and many interacting elements [3]. The multi-dimensional nature of innovation makes it difficult for research purposes as well as in practice. Many scholars with diverse backgrounds have studied different aspects of innovation that makes the literature fragmented. This diversity has resulted in applying varieties of approaches to innovation evaluation or measurement [1]. However, this diversity in measurement indicates the need for a holistic framework for evaluation but this task would not be unproblematic and requires a challenging endeavor. Thus developing such a comprehensive framework could be a big step towards a better understanding of innovation and its management by practitioners and scholars.

Having in place a holistic framework would be of assistance in decision-making by practitioners and policymaking as well as governments. As discussed earlier, much if not most of the innovation evaluation literature relied heavily on technology hiring, R\&D practices, patent or publication counts and other types of investments. However, there are many methods for innovation evaluation in the literature but almost no one covers all the aspects of it [1]. This indicates a need for an integrative model or framework to promote innovation evaluation and to benchmark its outcomes. Measuring innovation requires many considerations rather than just measuring tangible inputs or short-term outcomes. It cannot be measured with a single indicator, its evaluation needs considering inputs, process and outcomes including both tangibles and intangibles.

There are problems with currently available models for innovation evaluation such as risk consideration, knowledge evaluation as well as subjective measures of innovation. Risk (and its effects on the results) of innovation is almost one of the neglected aspects of innovation evaluation in previous studies. 
Considering the significant concerns in innovation evaluation mentioned in the literature, in the current study it was decided to consider three different metrics for innovation evaluation: Input measures which are called Capacity Metrics, Process measures named Capability Metrics and Outcomes measures called Performance Metrics. For capacity evaluation both objective and subjective measurements can be applied. For example, the amount of money invested or numbers of employed experts are examples of quantitative measures and employees' attitude and customers' experience are qualitative measures in this regard. The proposed evaluation method for outcomes could be socio-economic impact analysis which allows both quantitative and qualitative measurement of the results while accounting for social and environmental impacts plus impacts of associated risks. It should be noted that the details of the measurement mentioned above is intended to be undertaken as the next step of this study and will be presented as a tool in near future.

Tangible inputs like capital invested in innovation or number of employees working in innovation roles are easily accessible and quick for evaluation. Thus these assets are selected most of the time as indicators for innovation evaluation while intangible assets play a crucial role in innovation process. These intangibles are mostly neglected in evaluation process as they are difficult to access and measure. It has been stated in the literature several times that intangible assets could be more important than tangible assets. In fact, they are undeniable requirements for today's knowledge-based economy.

Innovation process is important because what happens during innovation process directly affects the outcomes of innovative practices. Thus to have a better assessment and understanding of innovation, assessing the process itself is a must. The result of this evaluation can show the capability of organizations in managing the innovation process and would be an important criterion in innovation evaluation. At last, evaluating the outcomes of innovation which seems to be the most important aspect of it, we again encounter tangible and intangible outcomes. Some of these outcomes will be achieved in short term and others take longer to be achieved. Short-term outcomes like number of new products or patent or publication counts are more common in the literature because of accessibility and measurability but the broader and longer-term outcomes of innovation are sometimes missed. These are not easy to measure and might not be of interest to organizations and innovators. For example, private sectors usually do not care about the social and environmental benefits (as longer term outcomes) of their innovative implementations. What they are looking for is always what can enhance the performance of their organization in a shorter period of time.

Having considered all the points mentioned above reliable evaluation of innovation needs consideration of all the elements interacting in the innovation process as a whole. Figure 1 shows a schematic and an overall view of such a framework.

As it can be seen in figure 1, input category is shows the extent of the firm/project's investment in innovation. The inputs are sub-categorized to tangibles and intangibles which confirm that input includes both monetary and non-monetary elements. Tangibles inputs include two main groups of expenditures and statistics. Expenditures deal with monetary investment like capital invested, training, research and development. Statistics deals with numbers and contains for example the number of innovation roles, the number of new equipment, IT tools. Intangibles inputs include culture \& climate and organization. Under culture \& climate, there are elements like management support, vision (attitude), the degree of presence of blame culture, trust and flexibility of rules and regulation within the firm/project. Organization intangibles can comprise elements associated with the firm/project's structure, policies, regulation and strategies and how these are in favor of innovation.

Process category is called capability that represents the firm/project's ability to implement and manage the process of innovation in order to get the best results. The process is sub-categorized to five groups of project management, economic consideration, network and alliances, knowledge management and innovation measurement. Project management includes processes like risk assessment, procurement, technical reporting or project reviews. Under economic sub-category, there are processes like, demand analysis, commercialization and marketing. Network and alliances sub-category includes teamwork, ongoing communication, industrial linkage, stakeholder management and client/customer contact. Knowledge management comprises of factors like data and information gathering, knowledge repository, lessons learned or learning environment. Innovation measurement processes include method and metrics of measurement and other elements like measurement leadership. 


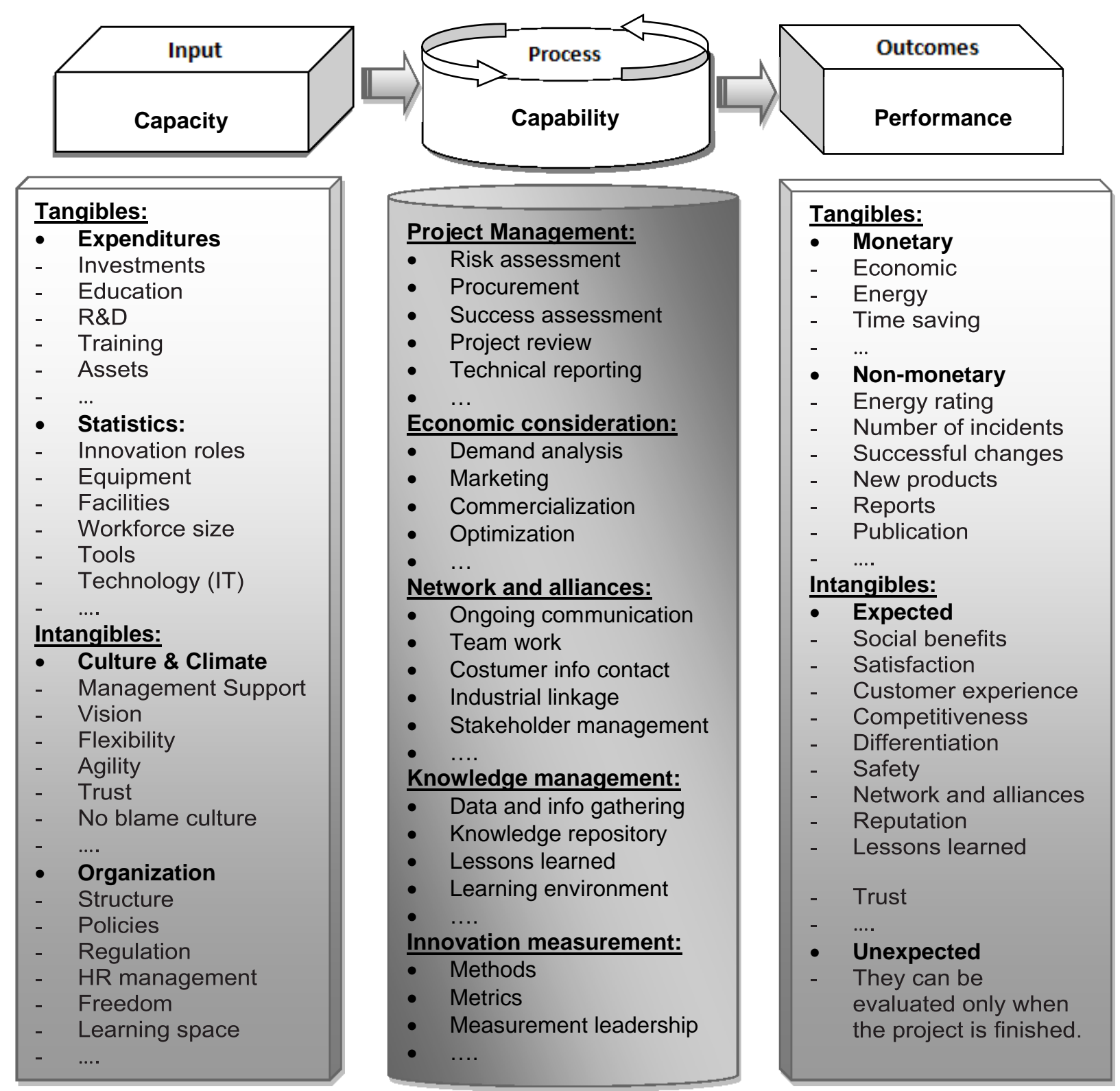

Figure1: Conceptual Framework for Innovation Evaluation

Outcome as the most important part of the evaluation is called performance indicator. The outcomes are important in the sense that the extent of success for innovative practices can be evaluated via the outcomes. Again for outcomes, there are sub-categories of Tangibles and Intangibles. Tangible outcomes can then be subcategorized to Monetary and Non-monetary outcomes. Monetary outcomes are associated with economic consideration and include cost, revenue and time. Non-monetary outcomes deal with numbers and statistics like the number of successful changes, the number of new generated ideas, the number of reports and publications, the number of new products or processes. Intangibles outcomes are then sub-categorized to Expected and Unexpected groups. Expected intangibles include a whole range of non-monetary outcomes like social benefits, satisfaction, customer experience, differentiation, safety, reputation, trust and competitiveness. Unexpected outcomes cover whatever that cannot be predicted until the project is finished. 
It should be mentioned that there are other external elements that affect innovation from outside which can be called external innovation climate. Government policies and regulations are examples of these kinds that can promote or inhibit innovation. However this climate surrounds organizations is important to be considered but their effects are out of organizations' or projects' control thus these elements are not considered in this study. In other words, those are excluded from the proposed framework. The purpose and scope of this paper do not allow including them in the framework but obviously this exclusion does not diminish their importance.

\section{INDUSTRY SURVEY AND FEEDBACK}

In order to initially validate the proposed framework twenty structured interviews were conducted with industry practitioners from companies dealing with infrastructure and major construction projects. This section covers the findings of these interviews.

\subsection{Industry interviewees' characteristics}

Among the interviewees there were six females (30\%) and fourteen males (60\%). They were from a range of age groups from 30 to 70 years old. Six of them were between 30 to 34 years old (30\%), eleven were between 35 to 45 years old (55\%) and three were older than 45 years (15\%). The interviewees were experienced in the industry from five to fifty years. Seven (35\%) had experience of 5-9 years, ten people (50\%) with 10-19 years of experience and three (15\%) had more than 20 years of working experience. In terms of position, eight people $(40 \%)$ were in management positions and twelve (60\%) were in engineering and senior engineering positions.

Table5: Characteristics of interviewees

\begin{tabular}{|l|l|c|c|}
\hline \multirow{2}{*}{ Total number } & \multicolumn{2}{|c|}{20} & Percent \\
\hline \multirow{4}{*}{ Age } & Female & 6 & $30 \%$ \\
\cline { 2 - 4 } & Male & 14 & $70 \%$ \\
\hline \multirow{4}{*}{ Experience } & $30-34$ years & 6 & $30 \%$ \\
\cline { 2 - 4 } & $35-45$ years & 11 & $55 \%$ \\
\cline { 2 - 4 } & $45+$ years & 3 & $15 \%$ \\
\hline \multirow{3}{*}{ Position } & $5-9$ years & 7 & $35 \%$ \\
\cline { 2 - 4 } & $10-19$ years & 10 & $50 \%$ \\
\cline { 2 - 4 } & $20+$ years & 3 & $15 \%$ \\
\hline \multirow{4}{*}{ Qualification } & Manager & 8 & $40 \%$ \\
\cline { 2 - 4 } & Engineer/seniors & 12 & $60 \%$ \\
\cline { 2 - 4 } & PhD & 2 & $10 \%$ \\
\cline { 2 - 4 } & Masters & 12 & $60 \%$ \\
\cline { 2 - 4 } & Bachelor & 5 & $25 \%$ \\
\cline { 2 - 4 } & Advanced & 1 & $5 \%$ \\
\hline
\end{tabular}

6.2. Discussion of the comments on the framework

Almost all the interviewees believed that the framework was well organized and acceptable however some of them had a few comments which are summarized in the following paragraph.

One of the interviewees stated that experience as an input to the process of innovation could be added under intangibles which seemed to be appropriate to be included under the "Organization" category. Another interviewee believed under "Culture \& Climate" category, education system of professionals and labors needs to be added. The authors believe that this factor has already been considered under tangibles in the expenditure category. Two people felt that the framework is complicated and must be simplified for each project also another person guessed that the framework would be difficult for implementation. The authors believe that however the framework might look complicated but care should be exercised in terms of simplification in order not to void the comprehensiveness of the framework. It should be mentioned the framework can be modified for different projects by the users. On the other hand, by further developing the framework (as a tool) the complication issue will be rectified and it will look simpler. There were two people with positive feedback on comprehensiveness of the framework suggesting the test of the framework with real- 
world projects which would be the next step for the current article. In fact the framework is intended to be further developed as a tool in order to become applicable in the real world cases. Another interviewee suggested adding sustainability and integrity of the proposed innovative solutions to the outcomes elements however the authors believed that these impacts were covered under the project management and economic consideration under process evaluation. One of the interviewees came up with the idea of including the health of employees somewhere in the framework which will be considered in further development of the tool possibly not only as input to the process of innovation but also as an outcomes of the process. Last but not least was a comment in regard to the accuracy of evaluation undertaken by the framework which authors stated that during the course of the study and in different reports and articles that the framework or the tool (which will be developed soon) could be used as an decision-making tool and the results could not be considered as precise measurement figures. In fact, in pursuit of innovation evaluation, subjective assessment and evaluation should be tolerated otherwise a comprehensive evaluation of innovation might not be even possible.

The interviewees were asked another question by which their views were captured on the importance of input, process and outcomes of innovation in infrastructure projects. The majority of interviewees (45\%) have chosen the outcomes as the important part to be considered in evaluation. They believed the outcome is the only measure by which the success of innovation implemented could be evaluated. On the other hand, seven interviewed people $(35 \%)$ stated that the process factors would be the most important ones in terms of evaluation. Only one interviewee acknowledged that the input to the process of innovation would be his preference for evaluation. Another two felt considering the integrity of evaluation all three categories of input, process and outcomes should be considered. There was also one person commenting that based on the case the evaluation might be done based on each those three categories.

\section{CONCLUSION AND FINDINGS}

Innovation evaluation was studied by reviewing the current literature that was very diverse and fragmented. It was demonstrated that however the current models have contributed significantly to the literature but still there is a considerable room for improving innovation evaluation and measurement especially in the infrastructure industry that seems to be behind in this trend of enhancement. It was discussed that the literature lacks a consensus and a holistic view on innovation evaluation and to provide a common understanding among practitioners and scholars there is a real need for a holistic evaluation framework to prevent partial or incomplete evaluation. A theoretical framework for evaluation of innovation in infrastructure projects was proposed. The proposed framework was critiqued by the industry practitioners. This research is in line with previous studies on innovation evaluation and its contribution to the literature is twofold. First, it studied innovation evaluation in a new context (infrastructure industry) which remained almost unstudied. Secondly, the proposed framework has been developed from a holistic point of view which considered almost all interacting elements in the innovation process. This study opens a window to what needs be done in future, and it can act as an opening step towards a more reliable evaluation of innovation in infrastructure projects. The next step of this study would be further developing the framework to produce an empirical tool for evaluating innovation and its outcomes. This detail evaluation can provide a deeper understanding on tangibles and intangibles outcomes of innovative practices in infrastructure projects.

\section{FUTURE RESEARCH}

Future research is planned to include the development of a tool to evaluate the outcomes of innovation in infrastructure projects as well as the identification of characteristics of the collaborative working environment for infrastructure projects to generate more innovative ideas and facilitating their implementations. 


\section{REFERENCES}

[1] R. Adams, J. Bessant, and R. Phelps, "Innovation management measurement: A review," Int. J. Manag. Rev., vol. 8, no. 1, pp. 21-47, 2006.

[2] Infrastructure Australia, "Infrastructure Australia's Reform and Investment Framework." Infrastructure Australia, pp. 1-29, 2012.

[3] E. Milbergs and N. Vonortas, "Innovation metrics: measurement to insight," Cent. Accel. Innov., vol. 1.4, 2004.

[4] P. J. Higgins and S. Green, Cochrane Handbook for Systematic Reviews of Interventions. John Wiley \& Sons, 2011.

[5] OECD, "The measurement of scientific and technological activities-Oslo Manual," 2005.

[6] NESTA, "The Innovation Index: Measuring the UK"s investment in innovation and its effects," London, 2009.

[7] N. Rosenberg, "Innovation and economic growth," OECD, pp. 1-6, 2004.

[8] OECD, Oslo manual: Guidelines for collecting and interpreting innovation data, 3rd Editio. European Communities: OECD and Eurostat, 2005.

[9] C. Schramm, A. Arora, and R. Chandy, "Innovation measurement: Tracking the state of innovation in the American economy," Washington DC, 2008.

[10] J. Delmon and T. W. Bank, "The Importance of Infrastructure," vol. 1, no. January, 2011.

[11] D. R. Spitzer, Transforming Performance Measurement: Rethinking the Way We Measure and Drive Organizational Success. New York: American Management Association (AMACOM), 2007.

[12] DTF, Investment Evaluation: Policy and Guidelines. Melbourne, Victoria: The Department of Treasury and Finance, 1996.

[13] A. Sood and G. Tellis, "Innovation Does Pay Off-If You Measure Correctly," Res. Technol. Manag., no. August, pp. 13-15, 2009.

[14] L. Morris, "Innovation Metrics: The Innovation Process and How to Measure It," 2008.

[15] B. Tether, "Identifying innovation, innovators and innovative behaviours: A critical assessment of the Community Innovation Survey (CIS)," Manchester, No. 48, 2001.

[16] DTI, "Innovation in the UK: Indicators and Insights," UK, 2006.

[17] HMT, "The ten-year Science \& Innovation Investment Framework Annual Report 2005," London, 2005.

[18] DISR, "Working towards a measurement framework for public sector innovation in Australia," Department of Innovation, Industry, Science and Research, 2011. 
[19] J. Andresen, B. Björk, and M. Betts, "A framework for measuring IT innovation benefits," vol. 5, no. January, pp. 57-72, 2000.

[20] M. Murphy, G. Heaney, and S. Perera, "A methodology for evaluating construction innovation constraints through project stakeholder competencies and FMEA," Constr. Innov., vol. 11, no. 4, pp. 416-440, 2011.

[21] E. Pellicer, U. P. De València, C. L. Correa, and U. Católica, "Organizational Improvement Through Standardization of the Innovation Process in Construction Firms," Eng. Manag. J., vol. 24, no. 2, pp. 40-53, 2012.

[22] A. Aizcorbe, C. Moylan, and C. Robbins, "Toward better measurement of innovation and intangibles," Surv. Curr. Bus., no. January, pp. 10-24, 2009.

[23] C. Corrado, J. Haskel, C. Jona-Lasinio, and M. Iommi, "Intangible Capital and Growth in Advanced Economies : Measurement Methods and Comparative Results," Germany, 2012.

[24] B. Hall, J. Mairesse, and P. Mohnen, "Measuring the Returns to R\&D," in Handbook of the Economics of Innovation, B. Hall and N. Rosenberg, Eds. 2009.

[25] S. Rose, S. Shipp, B. Lal, and A. Stone, "Frameworks for Measuring Innovation: Initial Approaches," Athena Alliance, Washington DC, 2009.

[26] C. Bloch, "Measuring Public Innovation in the Nordic Countries ( MEPIN ) Participants :," Copenhagen, 08207, 2011. 


\section{University Library}

\section{- M M N E R VA A gateway to Melbourne's research publications}

Minerva Access is the Institutional Repository of The University of Melbourne

Author/s:

Maghsoudi, S;Duffield, C;Wilson, DI

Title:

Innovation Evaluation: Past and Current Models and a Framework for Infrastructure Projects

Date:

2015

Citation:

Maghsoudi, S., Duffield, C. \& Wilson, D. I. (2015). Innovation Evaluation: Past and Current Models and a Framework for Infrastructure Projects. International Journal of Innovation Science, 7 (4), pp.281-298. https://doi.org/10.1260/1757-2223.7.4.281.

Persistent Link:

http://hdl.handle.net/11343/58250 